\title{
From degeneration to infection/inflammation, and from individual-centered to ecologic approaches to investigation of evolving patterns of diseases occurrences in populations
}

\author{
Da degeneração à infecção e da abordagem centrada \\ no indivíduo à investigação ecológica dos padrões \\ de ocorrência de enfermidades nas populações
}

M aria Inês Reinert Azambuja 1

\begin{abstract}
Variation in attributes of $\mathrm{CHD}$ cases over time suggests a temporal change in the source sub-population of cases. It is proposed that an early 20th century expansion of a CHD-prone sub-population, characterized by high-serum cholesterol phenotype and high case-fatality - and which contributed with most of the CHD cases and deaths during the 1960s - may have followed the 1918 Influenza Pandemic. The extinction of those birth-cohorts would have resulted in a relative increase in cases coming from a second source sub-population, characterized by insulin resistance and chronic expression of low grade inflammation markers, comparatively less vulnerable to acutely die from CHD. This re-interpretation of the CHD trend, and the abandonment of the idea of degeneration for inflammation/infection calls for a change in epidemiology. Besides exposures (diet, infection...), temporal variations in proportional representations of inherited and acquired phenotypes associated with individual resistance/vulnerability, would be important determinants of evolving patterns of diseases occurrences in populations.
\end{abstract}

Key words Influenza, Heart disease, Epidemic, M ortality, Ecologic studies
Resumo A variação registrada nos atributos dos casos de D oença Isquêmica do Coração (DIC) ao longo do tempo sugere variação temporal na subpopulação fonte dos casos. Propõe-se que tenha ocorrido, em associação com a Pandemia de Influenza de 1918, a expansão de uma subpopulação caracterizada por um fenótipo de hipercolesterolemia e alta propensão à mortalidade por DIC, queteria contribuído com a maior parte dos casos e dos óbitos por DIC registrados na década de 1960. A progressiva extinção daquelas coortes de nascimento teria resultado em crescimento relativo dos casos de DIC oriundos de uma segunda subpopulação, caracterizada por resistência à insulina e expressão de marcadores associados a inflamação crônica subclínica. Esta re-interpretação da tendência temporal da mortalidade por DIC, e o abandono da idéia de degeneração pela idéia de inflamação/infecção pede por uma mudança na epidemiologia. Além de exposições ambientais (di eta, infecção), variações temporais nas representações proporcionais de fenótipos associados à resistência e à vulnerabilidade individual seriam importantes determinantes dos padrões de ocorrência de doenças em populações. Palavras-chave Influenza, Doença cardiovascular, Epidemia, M ortalidade, Ecologia humana

1 Faculdade de M edicina,

UFRGS.

Rua Ramiro Barcelos 2600,

4o andar, 90035-003,

Porto Alegre RS Brasil.

miazambuja@via-rs.net 
How absurd... was the classical view of the heart as the "spring of all heat". Knowing so little, the ancients should have attempted no explanation of the matter; whereas we, today, with all our facts, are now able to show that bodily heat is simply the mechanic result of the velocity of blood in its circulation (Boerhaave, 1751).

For about 50 years, the degenerative paradigm had a strong influence in the way we conceived "causality" and "patterns of diseases occurrence in populations." During the last decade, it has lost its original strength. Several conditions earlier assumed to be degenerative, among them atherosclerosis, have now been increasingly described as inflammatory. The emergence of AIDS re introduced infection and its correlates - immune response, resistance/vulnerability - to the scientific fore. Molecular biology and genetics have also contributed to the growing understanding that variability is a central issue in the study of disease causation.

We will borrow from R. Lewontin (2001) and S. J. Gould (2001) the concepts of Platonic versus Darwinian understanding of nature, and how each of them explains changes of systems through time, to re-interpret changes in CHD associated features over time, and further explore possible implications of substituting inflammation for degeneration as the main idea behind causation.

The degenerative paradigm is in accordance with the traditional typological Platonic understanding of nature, where events are defined by their average presentation - conceived as typical, the essence representative of the whole - while actual variations are seen as imperfect or accidental realizations of the idealized types. The degenerative paradigm assumes that a same law-like history would be lived by each individual during its lifetime. Within this framework, disease would be modeled as resulting from some external factor (lifestyle, diet) affecting qualitatively similar individuals. That would justify individual-centered epidemiologic studies. Individuals are similar. What changes is the environment. Also, according with this interpretation, a temporal change in the population average serum cholesterol level, for example, would be expected to represent a movement of the whole distribution of individual values in the same direction. According to G. Rose (1985), preventive interventions at the population-lev$\mathrm{el}$, on exposures identified as risk factors at the individual level, should reduce mortality by bringing the whole distribution of risk "to the left".

Contrarily to the degenerative idea, the inflammatory/infectious paradigm conforms better to the requirements of the modern Darwinian understanding of nature, which sees reality as variation, as multiform individuals within populations. As stated by Stephen Jay Gould (2001), we have a strong preference for seeing trends as entities moving somewhere. H owever, trends may be reflecting instead relative expansions and retractions of different sub-populations integrating the system (Gould, 2001). The ensemble changes not because each individual undergoes the same law-like history... It changes as a whole by a change in the proportional repre sentation of different [sub-populations], which are themselves unchanging in their properties (Lewontin, 2001).

Trends in CHD death-rates might gain a different interpretation, under the Darwinian understanding of nature.

The 20th Century rise in CHD mortality was a worldwide phenomenon described by the WHO in 1969 as "thegreatest epidemic mankind has faced" (apud Gordon \& Kannel 1971). In the United States, during the 1960s, CHD responded for $35 \%$ of the overall mortality (Havlick \& Feinleib, 1978). The fall came unexpectedly. Between 1970 and 2000, CH D death-rates had declined 58 percent ( $\mathrm{NHLBI}, 2000)$. Reasons for it remain unclear. Similar trends were recorded in several countries (Thom, 1989).

During the decline, CHD attributes, pathogenetic concept and main associated risk factors experienced interesting modifications:

1) There was a continuing improvement in survivorship. Declines in case-fatality rates for myocardial infarction and in rates of re-infarction are well documented (Elveback, 1978; Rosamund et al., 1998). The age of patients presenting with myocardial infarction and unstable angina increased, suggesting that, nowadays, $\mathrm{CHD}$ is delayed and possibly less severe in its initial clinical presentation (Pepine, 1997).

2) The idea behind atherogenesis changed from degeneration to inflammation. During the 1960s, hypercholesterolemia had been considered the hallmark of atherosclerosis, a condition understood as a bland lipid storage disease (Libby et al., 2002). Its acute complications were attributed to high-grade coronary stenosis. Those concepts were reassessed during the 1990s. Inflammation rather than plaque size is 
now established as determinant of plaque instability and thrombosis (Libby et al., 2002). Additionally, low-grade chronic inflammation has been found to predict cardiovascular events, independently of the severity of the atherosclerotic burden (Libby et al., 2002; Ridker et al., 2002). According to Ridker et al. (2002), C-reactive protein may now be a stronger predictor of cardiovascular events than LDL serum cholesterol levels.

3) Average population levels of distinct metabolic markers associated with CHD cases changed in opposite directions. National surveys conducted between 1960 and 2000 indicate that mean serum cholesterol levels in US adults have consistently declined in all age-sex groups over the last four decades (CDC, 2003a). On the other hand, prevalence of overweight increased during the period (CDC, 2003b). During the last 30 years (Welborn \& Wearne, 1979; WHO, 1994) insulin resistance and its associated features - hypertriglyceridemia, low HDL, smalldense LDL, hypertension and overweight emerged as a "second atherogenic phenotype" (Ziegler et al., 1998), to become the main determinant of CHD cases (Rapp, 2002).

Changes mirroring the ones described above may have occurred during the rise in CHD mortality.

Before being considered a degenerative condition, the "atheromatous affections of arteries" had been described as inflammatory by Rudolf Virchow in 1858 (Virchow, 1989): one who knows that the fatty degeneration is here only a termination, and that the process is really a formative one, inasmuch as it begins with a proliferation - he can readily imagine the possibility of another termination, namely ossification... As soon as the real ossification exists, we cannot help regarding the process as one which has arisen out of irritation of the parts stimulating them to new, formative actins; so far therefore it comes under our ideas of inflammation, or at least of those processes which are extremely nearly allied to inflammation.

According to O sler (1908), four great factors [were involved] in the causation of atherosclerosis - the normal wear and tear of life, the acute infections, the intoxications [including smoking, diabetes mellitus, obesity], and those combinations of circumstances which keep the blood tension high (apud N ieto, 1998) - the same factors blamed after the epidemic era. And a comparison of CHD cases identified during autopsies made in two periods, 20 years apart, during the rise in CHD mortality, showed that, in 1931-1935, the odds of finding hypertensive disease among cases of coronary occlusion was 5:1. Comparatively, in the period 1951-1955, not only the degree of atherosclerosis found in males from all age-categories was considerably greater, but the odds of finding hypertensive disease among cases had reversed to 1:2.5 (Spain, 1960). As stated by that author, since there is no reason for assuming that the incidence of hypertensive disease had significantly decreased over this period, we are perhaps justified in concluding that this findings indicate a considerable increase in coronary atherosclerotic heart disease with occlusion that is entirely independent of hypertension as a factor in its pathogenesis.

This possible alternation of main phenotypes and pathogenetic mechanisms seen in association with CHD cases during the last 150 years (insulin resistance / inflammation (18501910) - high-serum cholesterol / "degeneration" (1920-1970) - insulin resistance / inflammation (1980-2000)) suggests a temporal variation in the main source subpopulation of cases. If this is the case, we should probably interpret the 20th Century trend in CHD mortality as a sum of trends on two different conditions both called CHD - coming from two different source subpopulations: one characterized by high-serum cholesterol levels and high case-fatality, which contributed with most of the CHD cases and deaths seen during the 1950s and 60s; and the other characterized by insulin resistance and chronic expression of low grade inflammation markers, which probably contributed to the pool of CHD cases and deaths during the whole period, but with comparatively lower rates of acute lethality.

Re-interpreting the change in CHD mortality as a change in the proportional representation of different subpopulations over time, which are themselves unchanging in their properties, would pose different questions regarding causes of CHD occurrence, such as: why (and how) did the high-serum cholesterol subpopulation decrease after the 1960s, and more important, why (and how) did it grow so fast and so much during the first half of the 20th Century? Should CHD cases originating from different phenotypic subpopulations be considered the same disease? Would it have happened before? If changing patterns of resistance/vulnerability (inherited and acquired phenotypes) were behind patterns of diseases occurrence in populations, how could the processes leading to 
them be identified? What would be the implications of this re-interpretation for public health policies?

A previous attempt of explaining the rise and fall in CHD mortality through an acquired variation in population vulnerability to atherogenesis and CHD-related deaths suggested a role for the 1918 Influenza pandemic in the process (Azambuja \& Duncan, 2002). Vulnerable individuals from cohorts born around 1870-1910, which met pandemic-related $\mathrm{H} 1$ influenza virus at ages 20-40 (during the Pandemic and subsequent epidemic waves) and survived, may have been "primed" by that encounter to late development of CHD. M imicry between amino acid sequences involved in cell attachment of viral haemagglutinin and those of apolipoprotein B involved in LDL binding to high affinity LDL receptors (Pleskov et al., 1994), co-localization of anti-apo $B$ antibodies at sites of viral penetration in the vascular bed, and bursts of cross-reactive self-immune response upon new influenza infections, could explain hypercholesterolemia (Kannel, 1974), intimal LDL accumulation (Steinberg \& Witzum, 1990) and the enhancement of CHD mortality seen during subsequent influenza epidemics (Collins, 1932; Eickoff et al., 1961; Gordon \& Thom, 1975). The gradual dying out of those birth-cohorts from the general population since the mid-1960s would explains the decline in CHD mortality and changes in attributes, pathogenesis and main associated risk factors among more recent CHD cases: during the decline, a proportionally growing number of CHD cases were coming from a second subpopulation characterized by insulin-resistance and low-grade inflammation. While we have called them both CHD, if what defines a disease is its subjacent pathogenic process, they should not be considered a same condition (Azambuja, 2004 [in press]).

H istorical records (Willius, 1945; 1946) indicate a possible occurrence of a previous rise and fall in CHD mortality in Britain over the last third of the Eighteenth Century (Azambuja, 1995). Heberden's original description of the anginal syndrome in 1772 (apud Willius, 1945), a time when its cardiac origin had not yet been established, followed a period of significant influenza activity in Britain, with epidemics of flu being recorded in 1727, 1732, 1737 and 1760 (Crosby, 1990).

It is reasonable to assume that in a situation of a common exposure, like high saturated-fat diet or an infectious epidemic, disease and death would probably be distributed not according with exposure, but according with patterns of vulnerability (and competing causes of diseases and deaths) specific to each population at a given moment. The denominators of occurrence equations are qual itatively different at different times, because they are constituted by varying representations of subpopulations with different experiences and rates of survival to them, over time. How to identify the processes responsible for the patterns we see?

Possibly, contrasting morbid-mortality patterns across birth-cohorts, geographic and socio-demographic groups would be a good initial approach to uncover clues to those subjacent processes (Levins \& Lopez, 1999). Reference points aimed to define, for example, ranges of birth-cohorts to be contrasted, ought to be established from the data or through hypothesisoriented external information.

A hypothesis to be further investigated, considering the proposed association between the 1918 Influenza Pandemic and the rise in CHD mortality, would be the role of influenza viruses in evolving patterns of human diseases. Influenza viruses have co-evolved with human populations for centuries. Their encounters may have resulted in varying patterns of relative distribution of adaptive capabilities (selected genotypes and adapted phenotypes - e.g. immune profiles) of human populations to new environmental challenges, over time and across space. During the past decade, Influenza has been recognized as an ideal system for investigating ecologic and evolutionary issues (Earn et al., 2000; 2002; Ferguson, 2003). M athematic modeling has been increasingly used to explore the evolutionary dynamics emerging from the adjustment between viral populations and immune phenotypes (Earn et al., 2002; Ferguson, 2003). It seems, however, that our culture of attributing disease to external agents has still "biased" those studies towards the understanding of the evolution of the virus. An alternative would be to use the influenza system to unravel the evolution of patterns of vulnerability in human populations.

The epidemiology we have today is the epidemiology developed under the degenerative paradigm. According to it, the CVD epidemic is moving from developed to developing countries, expectedly becoming their greatest killer around 2020. (Lenfant, 2001; Epping-Jordan, 2001). To prevent it, less developed countries 
have been convinced to extend health care access to all, sick and health, and invest in changing their health systems to offer care to chronic instead of acute conditions (Whelan, 2002). M ost of such preventive approach depends on widespread consume of drugs. But while huge (and maybe unnecessary) investments are done in health care, we still know very little about causes of disease occurrence, and less then we should on their distribution in the population.

If the Influenza hypothesis is right, and the 20th Century rise in CHD mortality resulted from an infectious-related expansion of a CHDprone subpopulation which has al ready faded out, migration of that CHD epidemic from developed to developing countries won't happen. Actually, a comparison of CHD mortality between the US and Brazil for the year 1999 (Azambuja, 2003) shows that CHD deaths are still much more frequent in the US, and highly concentrated among old-age individuals. The proportionally higher amount of CHD deaths at youngest ages in Brazil, compared to the US, is in accordance with the age-distribution of our population. While both populations have approximately the same size at age 35 , from age 75 onwards the US has 4 times more men and 5 times more women than we have in Brazil. On the other hand, after taking in account the agedistributions of both populations, stroke-related mortality seems to be higher here and to be killing men and women at youngest ages here compared to the US.

The paradigm has changed. To advance epidemiology under the infectious/inflammatory paradigm, a transition from a Platonic to a D arwinian habit of thought will be necessary. Standardized rates and stereotyped programs, which make no allowances for variability inside and between populations, are not informative or really effective in changing reality. Patterns of diseases occurrences are contingent. "Populations in continuing movement" must be the object of study of this new Darwinian epidemiology. And it is for this new object that new epidemiologic methods must be conceived.

\section{References}

Azambuja M I \& Duncan BB2002. Similarities in patterns of mortality from influenza A (H 1N 1 strains) in the first half of the 20th century and the rise and fall of coronary heart disease: a new hypothesis concerning the CHD epidemic. Cadernos de Saúde Pública 3:557577.

Azambuja MI 2003. Estudo comparativo sobre a mortalidade atribuída às doenças cardiovasculares nos EUA e no Brasil no ano de 1999. Ciência e Saúde Coletiva 8(2):583-584 (abstract).

Azambuja M I 2004. Spanish flu and early 20th Century expansion of a CHD-prone subpopulation. Texas Heart Institute Journal 2004 [in press].

Azambuja MI 1995. Rise and fall in ischemic heart disease mortality: it may have happened before. Revista de Saúde Pública 29:440-443.

Centers for Disease Control and Prevention, National Center for Health Statistics, National H ealth Examination Surveys and National Health and Nutrition Examination Surveys 2003. Serum cholesterol levels among persons 20 years of age and over, according to sex, age, race, and $\mathrm{H}$ ispanic origin: United States, 196062, 1971-74, 1976-80, and 1988-94. <http://www.cdc gov/nchs/products/pubs/pubd/hus/tables/2002/02hu s069.pdf>. Last access in Aug 30, 2003.
Centers for Disease Control and Prevention, National Center for $\mathrm{H}$ ealth Statistics, National Health Examination Surveys and $\mathrm{National} \mathrm{H}$ ealth and Nutrition Examination Surveys 2003. Healthy weight, overweight and obesity among persons 20 years of age and over, according to sex, age, race, and $\mathrm{H}$ ispanic origin: United States, 1960-62, 1971-74, 1976-80, and 198894. <http://www.cdc.gov/nchs/products/pubs/pubd/ hus/tables/2002/02hus070.pdf >. Last access in Aug 30, 2003.

Collins SD 1932. Excess mortality from causes other than influenza and pneumonia during influenza epidemics. Public Health Reports 47:2159-2179.

Crosby AW. America's forgotten pandemic: the influenza of 1918. Cambridge University Press, New York.

Earn DJD, Dushoff I \& Levin SA. Ecology and evolution of the flu. Trends in Ecology \& Evolution 17:334-340.

Earn DJD, Rohani P, Bolker BM \& Grenfell BT 2000. A simple model for complex dynamical transitions in epidemics. Science 287:667-670.

Eickoff TC, Sherman IL \& Serfling RE. Observations on excess mortality associated with epidemic influenza. JAM A 1961:176:776-782.

Elveback L 1978. Coronary heart disease in Rochester, M innesota, 1950-75: incidence and survivorship, pp 
116-123. In RJ Havlick \& M Feinleib (eds.). Proceedings of the conference on the decline in coronary heart disease mortality. Hyattsville, MD (eds): Bethesda, Maryland: National Heart, Lung and Blood Institute.

Epping-Jordan JÁ 2001. The challenge of chronic conditions: WHO responds. [Editorial]. BMJ 323:947-948.

Ferguson N M , Galvani AP \& Bush RM 2003. Ecological and immunological determinants of influenza evolution. Nature 422: 428-433.

Gordon T \& Kannel WB 1971. Premature mortality from coronary heart disease. The Framingham Heart Study. JAM A 215:1617-1625.

Gordon T \& Thom T 1975. The recent decrease in CHD mortality. Preventive M edicine 4:115-125.

Gould SJ 2001. Lance de dados. A idéia da evolução de Platão a Darwin. [Full House: The Spread of Excellence from Plato to Darwin] Record, Rio de Janeiro, 2001.

Havlick RJ \& Feinleib M (eds) 1978. Proceedings of the conference on the decline in coronary heart disease mortality. Hyattsville, MD (eds). National Heart, Lung and Blood Institute: Bethesda, M aryland.

Kannel WB 1974. The role of cholesterol in coronary atherogenesis. Emergency M edicine Clinics of N orth America 58:363-379.

Lenfant C 2001. Can we prevent cardiovascular diseases in low- and middle-income countries? Bulletin WHO 79:980-982.

Levins R \& Lopez C 1999. Toward an eco-social view of health. International Journal of $\mathrm{H}$ ealth Serv 29:261293.

Lewontin R 2001. (3rd printing). The triple helix. Gene, organism and environment. Harvard University Press, Cambridge, M assachussetts.

Libby P, Ridker PM \& M aseri A 2002. Inflammation and atherosclerosis. Circulation 105:1135-1143.

National Heart, Lung \& Blood Institute 2002. M orbidity $\&$ mortality: 2002 chartbook on cardiovascular, lung and blood diseases. US Department of $\mathrm{H}$ ealth and $\mathrm{Hu}$ man Services, National Institutes of Health: Rockville, Maryland.

Nieto FJ 1998. Infections and atherosclerosis: new clues from an old hypothesis? American Journal of Epidemiology 148:937-948.

Osler W 1908. Diseases of the arteries. In W Osler \& T M acCrae T (eds.) 1908. M odern medicine. Its theory and practice in original contributions by Americans and foreign authors. Vol. 4 Philadelphia, PA: Lea \& Fabiger, 426-47.

Pepine Cl 1997. Changing myocardial infarction population characteristics: reasons and implications. American Heart Journal 134:S1-S4.
Pleskov VM , Bannikov AI \& Zaitsev luv 1994. The receptor-mediated endocytosis of influenza viruses and low-density lipoproteins by tissue cells.Vopr Virusol 39:121-5.

Rapp RJ 2002. Hypertriglyceridemia: a review beyond low-density lipoprotein. Cardiology Review 10:163172.

Ridker PM , Rifai N, Rose L, Buring JE \& Cook NR 2002. Comparison of $\mathrm{C}$-reactive protein and low-density lipoprotein cholesterol levels in the prediction of first cardiovascular events. N ew England Journal of M edicine 347:1557-1565.

Rosamund WD et al. 1998. Trends in incidence of myocardial infarction and in mortality due to coronary heart disease, 1987 to 1994. NEJM 339:861-867.

Rose $G$ 1985. Sick individuals and sick populations. International Journal of Epidemiology 14:32-38.

Spain DM 1960. Problems in the study of choronary atherosclerosis in population groups. Journal N ew York Academic Sceince 84:816-834.

Steinberg D \& Witzum JL 1990. Lipoproteins and atherogenesis. Current concepts. JAM A 264:3047-3052.

Thom TJ 1989. International mortality from heart disease: rates and trends. International Journal of Epidemiology 18:S20-S28.

Virchow R 1989. Cellular pathology as based upon physiological and pathological histology. Atheromatous affections of arteries. Nutrition Reviews 47:23-25.

Welborn TA \& Wearne K 1979. Coronary heart disease incidence and cardiovascular mortality in Busselton with reference to glucose and insulin concentrations. Diabetes Care 2:154-160.

Whelan J 2002. WHO calls for countries to shift from acute to chronic care. News. BMJ 324:1237.

Willius FA 1945. The historic development of knowledge related to the coronary circulation and its diseases. The eighteenth century. Staff $M$ eetings of the $M$ ayo Clinic 20:326-336.

Willius FA 1946. The historic development of knowledge related to the coronary circulation and its diseases. The ninetheenth century. Staff M eetings of the M ayo Clinic 21:77-90.

WHO 1969. World Health Organization warns heart diseases are becoming mankind's greatest epidemic. Bull Int Soc Cardiol (1):1.Apud.

WHO 1994. Cardiovascular disease risk factors: new areas of research. Report of a WHO scientific group. WHO technical report series 841 , WH O, Geneve.

Ziegler O, Guerci B \& Drouin P 1998. [The "second atherogenic phenotype" or the role of insulin resistance in vascular risk]. Archives des M aladies du Coeur e des Vaisseaux 91(Spec 5):33-39.

Artigo apresentado em 16/4/2004

Aprovado em 19/7/2004

Versão final apresentada em 3/11/2004 